\title{
TEOLOGI SUFI \\ KAJIAN ATAS MISTISISME CINTA JALALUDDIN RUMI
}

\author{
Oleh: \\ Miftahul Jannah* \\ Program Studi Magister Aqidah dan Filsafat Islam \\ UIN Sunan Kalijaga Yogyakarta \\ mifta.more@gmail.com
}

\begin{abstract}
This paper will examine the idea of mycticisme love carried by Jalaluddin Rumi. In his journey as a Sufi, Rumi managed to take his own Sufism form and give a new nuance that was considered different from most Sufis of his time. Sufism thinking contained in the form of poetry and poetry known as the path of love (mystic love). This paper is a reseach library using descriptive analysis method to study the thoughts of Divine love Jalaluddin Rumi. The love carried by Rumi signals to live in harmony with the principles of peace and tolerance. Poetry becomes one of the most appropriate means to express the inner state he feels. With the idea of divine love he introduced, Rumi was able to pour all kinds of feelings and expressions of his personal religious experience into deeply poetic verses. Poems born of a heart yearning for union with the Beloved, until when the Beloved Being is the only being that exists. Love, which is the light of life and human values, is actually eternal. So it must be for the eternal. He does not deserve to be given to those who are destined to be mortal and perish.
\end{abstract}

Keywords: Jalaluddin Rumi, Sufi, Mysticism Love

A. PENDAHULUAN
Dalam Tasawuf, pada
umumnya memandang manusia
terdiri dari dua substansi yaitu:
subtansi yang bersifat materi (badan)
dan substansi yang bersifat immateri
(jiwa), dan bahwa hakekat dari
manusia adalah substansi
immaterialnya. Ketinggian dan

kesempurnaan manusia diperoleh dengan memfungsikan substansi immaterial itu, dengan jalan mempertajam daya-daya yang dimilikinya. Dengan subtansi immaterial ini, para sufi berusaha untuk mencapai tingkat kesempurnaan yang tertinggi sehingga mereka memperoleh 
pengetahuan tentang hakekat kesempurnaan (cinta Ilahiyah).

Pembahasan mengenai cinta sudah mewarnai khazanah pemikiran Islam sepanjang sejarah. Teori cinta menempati posisi penting dalam perbincangan tentang relasi manusia baik dengan sang pencipta maupun dengan alam atau sesama makhluk. Seiring dengan perkembangan zaman tema cinta semakin mencuat ke permukaan bersamaan dengan hadirnya para intelektual muslim yang mengenalkan gagasan tentang cinta.

Jalaluddin Rumi, sufi yang sangat terkenal, telah mengambil bentuk sufisme tersendiri yang dianggap berbeda dari para sufi pada masanya, kebanyakan sufi-sufi terdahulu lebih cenderung untuk mengungkapkan masalah metafisik dan maqamat, berbeda dengan Rumi, pemikiran sufismenya memiliki nuansa tersendiri yang tertuang dalam bentuk sajak dan syair, sehingga ia dkenal dengan jalan sufinya jalan cinta (mistikus cinta). (Kinzer 1998, 2) Cinta yang diusung oleh Rumi mensinyalir untuk hidup harmoni dengan prinsip perdamainan dan toleransi. (Erkinovna 2018, 102) Menurut Rumi puisi adalah salah satu sarana paling tepat untuk mengu ngkapkan keadaan bhatinnya.

Rumi termasuk dari sekian banyak penyair yang mampu menciptakan gelombang kata-katanya menjadi sunami kehidupan, dalam arti ia mampu menghanyutkan jutaan manusia dari masa kemasa untuk menuju sebuah hakekat ketuhanan, kebebasan, kemuliaan dan tujuan hidup yang hakiki. Puisi-puisi
Jalaluddin Rumi dipenuhi dengan mistik, yang tidak semua orang mampu mengungkapkan nilai-nilai yang terkandung dalam puisipuisinya, serta karakteristik kemistikan yang masih dipenuhi kemisteriusan.

Para sufi juga berbeda-beda dalam mendefinisikan cinta, Rumi mendefinisikan cinta sebagai kecenderungan rasa kepada sesuatu secara total, ia lebih mementingkan cinta daripada diri sendiri, mempunyai sikap sukarela yang dipengaruhi oleh ketertarikan terhadap yang dicintai. (Khodady 2015, 205) Engkau akan selalu setia kepada yang dicinta baik ditempat sunyi ataupun terbuka. Beberapa sufi juga mengatakan "cinta juga laksana api dalam hati yang dapat membakar apa saja selain yang dicintai.

Rumi telah menuliskan; "Apapun yang aku katakan tetang cinta, ketika cinta datang, aku menjadi malu berbicara." Pada saat yang sama, jikalau cinta merupakan kekuatan yang esensial di dalam dan di balik alam semesta dan kehidupan batin kita ini, maka tidak ada subjek yang lebih utama. (Helminski 2005, 54)

Sebagaimana yang dikatakan oleh Rumi, bahwa cinta itu sulit untuk didefinisikan dan dimaknai. Dengan memberikan definisi, membuat makna cinta akan semakin samar. Definisi dari cinta adalah wujudnya itu sendiri, karena pada dasarnya definisi hanya berlaku untuk ilmu. Sedangkan cinta adalah sebuah keadaan rasa yang bergejolak ke dalam lubuk hati para pengagungnya. (Sammel 1986, 55) Tak ada yang 
dapat diutarakan kecuali perasaan cinta itu sendiri. Tak ada yang dapat dibicarakan tentangnya kecuali penjelasan tentang bekas-bekas yang ditinggalkannya, ungkapan atas buahnya dan segenap penjelasan tentang sebab-sebabnya. (Isa 2007, 200)

Cinta yang gagas oleh Rumi, mengedepankan untuk hidup harmoni dengan prinsip perdamaian dan toleransi. Dengan prinsip-prinsip yang demikian, akan membuka jalan menuju gerbang kellahiyan untuk menuju kepada cintanya yang sejati. Tentunya dalam mencapai cinta Ilahiyah tersebut memerlukan pemahaman yang mendalam. Untuk itu dalam tulisan ini akan dijabarkan tentang gagasan cinta Jalaluddin Rumi yang penuh dengan jalan mistis (mistic) dalam mencapai penyatuan diri dengan yang maha sempurna (Tuhan).

Tulisan ini tentu bukanlah penelitian pertama yang menganalisis pemikiran Jalaladdin Rumi, sebagai seorang penyair besar pemikirannya telah banyak diulas bahkan dijadikan penelitian akademik seperti skripsi, tesis maupun disertasi. Hanya saja dalam hal ini penulis merujuk kepada beberapa tulisan terdahulu yang dijadikan sebagai kajian literatur dalam penulisan jurnal ini.

Di antaranya yang di tulis oleh Ali Mansur dengan judul Maulana Jalaluddin Rumi (12071273): Telaah atas Keindahan Syair dan Ajaran Tasawufnya. Tulisan ini memfokuskan penelitiannya dalam melihat nilai-nilai sufisme yang terdapat dalam setiap syair-syair Rumi, syair-syair tersebut dikategorikan berdasarkan ajaranajaran tasawuf yang terdapat di dalamnya. Sebagai contoh, syairsyair yang membicarakan tentang tawakal, fana, mahabbah dan lain sebagainya.

Selain itu, penulis juga merujuk kepada jurnal yang ditulis oleh Halimi Zuhdy yang berjudul Mistik Jalaluddin Rumi (Analisa Struktural dalam Puisi Jalaluddin ArRumi). Penelitian ini tidak beda jauh dengan penelitian sebelumnya, yang menganalisa secara deskriptif nilainilai mistik dalam puisi-puisi Rumi baik dalam struktur batin atau struktur luar.

Dengan demikian, tulisan ini tentu saja berbeda dengan kajiankajian literatur di atas. Dalam hal ini, penulis akan melihat secara universal sisi mistisisme cinta Rumi yang akan dikaji dari keseluruhan struktural pemikirannya.

\section{B. METODE PENELITIAN}

Tulisan ini akan mengkaji tentang mistisisme cinta yang diusung oleh Jalaluddin Rumi. Dengan jenis penelitian kepustakaan (library reseach), yakni mengumpulkan data-data yang berkaitan dengan pembahasan baik berupa buku, catatan maupun hasil laporan dari penelitian terdahulu, (Hasan 2002, 11) yang digunakan untuk menghasilkan data-data yang diperlukan. Langkah awal dalam melakukan penelitian yakni dengan mengklasifikasikan data-data yang terkait pembahasan. Data tersebut kemudian diolah dengan menggunakan metode deskriptifanalisis, yaitu dengan 
menggambarkan objek pembahasan dan mengadakan perincian terhadap objek yang diteliti. (Moeleong 2004, 4) Melalui metode ini, persoalan akan dipaparkan secara gamblang dengan maksud untuk mengetahui pemikiran tasawuf Rumi terkhusus mistisisme cintanya.

\section{HASIL DAN PEMBAHASAN}

\section{Jejak Kehidupan dan Karya Jalaluddin Rumi}

Nama lengkap Rumi adalah Maulana Jalaluddin Muhammad bi Huss Alkhatbi, namun terkenal dengan nama Jalaluddin ar-Rumi. Nama julukan Rumi ini dikenakan kepadanya karena sang sufi menghabiskan sebagian besar hidupnya di Konya, Turki, yang dahulunya merupakan bagian dari wilayah kekaisaran Rumawi Timur (bangsa Arab menyebutnya ar-Rum). sebuah nama yg sudah tidak asing lagi ditelinga kita lahir pada tahun 1207 M di Balkhi. (Permadi 1997, 128)

Ayahnya bernama Jalaluddin Baha'uddin Muhammad yang lebih dikenal dengan nama Baha Walad, seorang tokoh ulama dan guru besar dinegerinya waktu itu yang juga bergelar Sultonul Ulama. Sebagai guru berkharisma besar, tidak heran jika fatwanya selalu didengar orang dimana-mana, hal itu memicu rasa iri sebagian orang, mereka lalu mencoba meluncurkan fitnah, dan mengadukannya kepada penguasa. Meskipun demikian simpati orang kepadanya sedikitpun tidak berkurang, pendapat dan fatwanya tetap dijadikan pedoman. Itulah sebabnya penguasa mengisyaratkan agar ia meninggalkan negeri. (Arberry 1996, 1)

Syekh Bahauddin Walad bersama keluarganya pindah ke Konya di suatu daerah yang bernama Rum (Turki). Setelah menetap dua tahun, dan pada tahun 638 ia meninggal dunia. Karena tinggal di daerah Rum, maka Rumi digelar dengan "Rumi" sedangkan nama aslinya ialah Jalaluddin. Setelah ayahnya meninggal Rumi menggantikan posisi ayahnya dalam bidang pengajaran dan pendidikan di sekolah Khadawandakar. Namun, kedudukan yang cukup tinggi itu tidak menghalangi dia tetap belajar, memperluas cakrawala pengetahuannya dan memperdalam ilmu-ilmunya. (Cyrus 2010, 244-245)

Bertahun-tahun Rumi menikmati ketenaran dan menempati posisi yang sangat terhormat sebagai pemimpin dan ulama ilmu-ilmu agama Islam di Konya, (Rustom 2018, 200) sampai suatu ketika terjadilah peristiwa yang mampu mengubah arus kehidupannya hampir secara drastis. Namun, justru kejadian itu pula yang menyebabkan namanya semakin terkenal dan berpengaruh. (Arberry 1996, 4-5)

Titik balik kehidupan Rumi terjadi ketika ia berjumpa dengan seorang sufi yang mengunjungi kota tersebut sebagai orang tua berusia 60 tahun. Namanya Muhammad bin Ali bin Malik Daad, tetapi lebih dikenal dengan "Syamsi at-Tabriz". Kejadian itu bermula ketika Rumi sedang memberikan pelajaran di depan khalayak umum, tiba-tiba seorang lelaki asing Syamsi Tabriz bertanya: "Apa yang dimaksud dengan riyadah 
dan ilmu?". Mendengar pertanyaan itu Rumi terkesima karena kiranya apa yang di sampaikan Syamsi Tabriz benar, tepat dan mengenai sasaran. Sejak saat itu ia dekat dengan Syamsi tabriz yang kemudian menjadi gurunya.

Peristiwa itu membuat Rumi seperti menemukan semangat baru, mendorongnya untuk meninggalkan ketenaran dan mengubahnya dari seorang teolog terkemuka menjadi seorang penyair mistik. (Rumi 2016, 8-9) Demikian kuatnya pesona kepribadian Syams Tabriz ini sehingga membuat Rumi menarik diri dari khalayak ramai dan ia mulai zuhud, uzlah.

Rumi benar-benar tunduk kepada gurunya, dimatanya Syamsi Tabriz benar-benar sempurna, bahkan keduanya tinggal bersama dalam sebuah kamar selama 10 hari. Ada juga yang mengatakan selama enam bulan Rumi dan gurunya mengasingkan diri di dalam kamar Shalahuddin tanpa seorangpun yang berani memasukinya. (Rumi 2016, 13) Demikian besarnya cinta Rumi kepada sang guru, lahirlah sajak cintanya :

"Cinta bagaikan penyakit tanpa obat

Setiap penderita meminta ditambahkan

penderitaannya

Dengan suka cita mereka berharap kepedihan dan derita dilipatgandakan

Takkan ada minuman di dunia yang manisnya melebihi racun ini
Takkan ada lagi kesehatan di dunia yang lebih baik dari penyakit ini

\section{Cinta memanglah penyakit}

Tetapi penyakit yang menyembuhkan semua penyakit

Siapa saja yang pernah mengidapnya

Takkan pernah lagi menderita penyakit lain".

Hal ini memunculkan fitnahfitnah yang membuat Syamsi Tabriz tidak nyaman berada didekat Rumi dan memutuskan pergi secara sembunyi-sembunyi dan meninggalkan Konya. Kejadian itu meninggalkan kesedihan yang mendalam bagi Rumi, dan ia mengalami semacam depresi. Sejak kejadian itu bakat-bakat sastranya mulai keluar dan syair-syairnya lahir, hingga suatu ketika lahirlah tarian sufi yang dimulai dengan memukulkan kedua kaki ke tanah, berputar-putar, tenggelam dalam alunan lagu-lagu ghazal untuk pelipur lara hatinya. (Rumi 2018, 5-8)

Kendati Rumi tidak berhasil menemukan Syamsi Tabriz, lamalama jiwanya menjadi tenang dan yakin bahwa ia adalah bagian dari gurunya. Ia berkata : "aku tidak akan mencari lagi, aku akan mencari diriku sendiri. Sebab, segala yang ada dalam diri Syamsi Tabriz juga ada dalam diriku". Ia berkata kepada dirinya "antara aku dan Syamsi Tabriz tidak ada bedanya" jika dia matahari, aku serbuk cahayanya. Jika ia laut, aku adalah bahteranya. Serbuk cahaya 
bersumber pada matahari dan kehidupan perahu (bahtera) pada laut.

Dengan berjalannya waktu
dan bertambahnya usia, jiwa
Jalaluddin Rumi semakin matang.
(Mansur 1996, 210) Fase-fase
kejiwaan telah dilaluinya dengan
baik. Selanjutnya Rumi mengangkat
salah seorang muridnya sebagai
sahabat rohaninya yang bernama
Celebi Hasamuddin. Hasamuddin
adalah murid Rumi yang spesial dan
mendapatkan kehormatan dari sang
guru, secara resmi ia di angkat oleh
gurunya ssebagai khalifah
(pengganti) dan juga dijadikan
sebagai sekretaris pribadi. Rumi
mengibaratkan sebagai Abu Yazid al-
Bustami dan Junaid al-Bagdadi,
dalam syairnya Rumi berkata:

"Dialah kunci khazanah
Arasy

\section{Dialah Bayazid hari ini, Junaid masa kini}

Dialah anakku, Dialah
bapakku

Dia cahaya bagiku sekaligus mataku"

pada tahun $672 \mathrm{H}$ Setelah menjalani kehidupan yang berliku, kesehatan Rumi mulai menurun dan jatuh sakit hingga akhirnya ia meninggalkan dunia pada 17 desember 1273 M. Ketika merasakan sakit yang terakhir, ia berkata pada sahanatnya, "di dunia ini aku merasakan dua kedekatan. Satu kepada tubuh dan satu lagi kepada kalian. Ketika, karena rahmat Tuhan, aku harus melepaskan diri dari kesunyian dan kehidupan duaniawi, kedekatanku kepada kalian akan tetap ada. (Rumi 2018, 12-14)

Sebagai seorang sastrawan, sufi, sekaligus ulama, Rumi banyak melahirkan karya. Karyanya dapat dibagi dalam dua jenis, prosa dan puisi. Karya Rumi yang berbentuk prosa terdiri dari tiga karangan, yakni 1), al-Majalis as-Sab'ah, 2) Fihi Ma Fihi, dan 3) Makatib. Sedangkan karya Rumi yang lainnya sebagian besar ditulis dalam bentuk sya'ir. Seperti Diwan Syamsi Tabriz. Masnawi Ma'nawi. Karya Rumi yang paling besar, (Sharma 2015, 188) menyajikan ajaran-jaran mistik Rumi dengan indah dan kreatif melalui sya'ir-sya'irnya. (Rumi 2013, 9-11) Ruba'iyat, Fihi Ma Fihi, Makatib, Majalis Sab'ah, himpunan khutbah Rumi di berbagai mesjid dan majlismajlis keagamaan.

\section{Mistisisme Cinta Jalaluddin Rumi}

Menurut Rumi ilmu pengetahuan saja tidak cukup dalam meraih ketentraman jiwa. (Kartanegara 2014, 29-30) Rumi menyadari bahwa dalam diri manusia ada kekuatan tersembunyi, yang apabila diberdayakan secara sungguh-sungguh, akan dapat memberi kebahagiaan dan pengetahuan yang tidak terkira luasnya, kekuatan tersembunyi itu ialah cinta. (Manni 2010, 164)

Cinta merupakan tema sentral yang menjadi pusat perbincangan Jalaluddin Rumi mengenai hubungan antara seorang hamba dengan Tuhannya. Bagi siapa pun yang ingin memasuki istana sakral ketuhanan, cinta Ilahi harus menjadi kendaraan 
utamanya melampaui kendaraankendaraan lainnya.

\section{Dalam pandangan Rumi,} kekuatan cintalah yang dapat mengantarkan seorang pencinta untuk mencapai keadaan yang maha indah, yang dapat merubah keadaan pahit menjadi manis, pengharapan yang berujung kepada kerinduan yang tiada batas. Rumi mengatakan bahwa penderitaan yang dialami oleh si pecinta merupakan tahapan yang harus dilalui sebagai bentuk dari proses pemurnian bathin yang akan selalu peka terhadap cahaya-cahaya ketuhanan yang menyinari bathinnya.

Dalam hal mencapai cinta Ilahi tersebut, Rumi memberikan gambaran tahapan yang sering dilakukan oleh para sufi, pada awalnya para sufi melakukan tahapan pembersihan atau pemurnian jiwa, selanjutnya jiwa yang telah melalui tahapan pemurnian hendaklah diisi dengan cahaya kebaikan untuk memurnikan iman, tahapan ini akan mengantarkan sang sufi untuk berada pada tahapan pencahayaan yang disinari oleh cahaya Ilahi, tempat di mana ia diberkahi oleh cinta dan kearifan dari sang Ilahi. (Schimmel 1996, 174)

Tahapan ini menjadi proses terakhir dalam penyatuan serta pengungkapan cinta, Ia merefleksi dalam setiap jiwa untuk menyaksikan segala sesuatu di luar penglihatan. Dalam istillah Schimmel disebut dengan "penyingkapan hijab ketidaktahuan", hijab atau penghalang yang menutupi unsurunsur Ketuhanan dan makhluk-Nya.
Pengungkapan cinta yang demikian menjadi dasar dalam mistik Islam, bagi berkembangnya tradisi puisi-puisi sastra atau sajak-sajak ahli mistik sebagai media dalam mengungkapkan rasa cinta, sesuai dengan pengalaman mistik yang dialami oleh masing-masing pecinta.

Walaupun dalam garis besar, hampir semua bentuk mistisisme memiliki ciri yang sama, khususnya kecenderungan akan paham keesaan wujud dan monoisme. Berdasarkan kaidah dan titik tolak pencarian masing-masing mistikus, sejumlah sarjana sering mengelompokkannya ke dalam beberapa kategori, misalnya Khalifah Abdul Hakim yang menyebutkan adanya persamaanpersamaan pandangan di antara para mistikus dalam beberapa hal;

a. hakikat wujud tunggal atau satu,

b. Semua fenomena merupakan aspek dari hakikat yang sama dan setap fenomena menuju pada hakikat yang sama pula,

c. Karena semua wujud fenomenal berasal dari hakikat terakhir, mereka mengembalikan kepada hakikat asal yang sama,

d. Hakikat wujud yang dapat diresapi dengan nalar dalam peringkat yang tinggi, membuktikan bahwa nalar bersifat komprehensif dan tidak parsial.

e. Pengetahuan tentang yang hakiki tidak dapat diserap melalui logika, pengamatan bathinlah yang merupakan 
pembimbing terbaik dalam menyerapnya,

f. Tujuan utama kehidupan ialah bagaimana seseorang dapat meresapi hakikat pengalaman rohani sebab hanya dengan cara ini, jiwa seseorang dapat bersatu kembali dengan Sang Hakikat,

g. Penglihatan batin disebut dengan "cinta" sedangkan pengetahuan tentang hakikat melekat dalam cinta,

h. Cinta yang demikian itulah yang merupakan sumber utama semua bentuk moralitas keagamaan dan adab yang tinggi. Tanpa cinta, semua agama dan moralitas akan menjadi formal dan mekanis. Tanpa cinta pula, pikiran akan tetap berada dalam kegelapan, tidak mampu untuk mencapai cahaya Ilahi. (Rifa'i 2010, 103)

Cinta bagi Rumi adalah rahasia ketuhanan dan rahasia penciptaan, oleh karena itu, ia tidak bisa didefinisikan, ia juga merupakan rahasia makhluk-makhluk-Nya yang dalam diri manusia disebut dengan potensi rohani yang dapat mengangkatnya naik ke tingkatan tertinggi penciptaan. Seperti yang dikutip oleh Schimmel, bahwa Rumi mengatakan pengalaman mistik dapat membersihkan penglihatan qalbu, sehingga qalbu dapat menyaksikan bahwa wujud hakiki adalah satu, sedangkan yang lainnya hanyalah nisbi, melalui pengalamannya, Rumi mengatakan bahwa yang nisbi akan lenyap oleh cinta dan kefanaan.
Tujuan yang hendak dicapai oleh Rumi melalui jalan cinta ialah mengenal Tuhan sebagai Wujud Hakiki yang meliputi semua wujud. Akan tetapi, Rumi menambahkan bahwa mengenal saja tidak ada artinya tanpa merasakan kehadiranNya dalam segala sesuatu, dalam segenap peristiwa, dalam kehidupan pribadi, dengan tujuan untuk merealisasikan persatuan dengan-Nya dalam semua aspek kehidupan. Tujuan lain yang tak kalah penting dari jalan cinta ialah mengenal jati diri atau diri kita yang sebenarnya. Agar bisa merasakan keistimewaan cinta dalam perspektif Rumi, tentu perlu dikedepankan beberapa point penting dalam gagasan cintanya:

\subsection{Keterbatasan Akal}

Rumi menilai akal melalui dua perspektif, dari satu sisi akal merupakan kapasitas yang memiliki tugas yang menakjubkan. Namun dari sisi lain, pada level yang lebih tinggi untuk mendekat kepada Tuhan, akal memiliki kelemahan tersendiri. Pada level pertama, akal adalah sebuah anugerah yang mampu mebedakan manusia dari binatang. Manusia dapat mengendalikan dorongan-dorongan rendah hawa nafsu dengan menggunakan akalnya dan menjadi seorang makhluk yang unggul dengan mengekang hasrat-hasrat liar jasmaninya. Bagi Rumi, akal juga merupakan sebuah cahaya sakral yang mengalir dalam hati, sehingga kebenaran dan kepalsuan dapat dibedakan melalui serpihan lenteranya.

Namun pada level yang lebih tinggi, akal tidak mampu membawa kita memasuki misteri ketuhanan, 
memasuki gerbang cinta Tuhan. Dalam perspektif Rumi, keterbatasan akal terungkap secara simbolis melalui "kisah ahli bahasa dan tukang perahu" seorang ahli tata bahasa pergi berlayar dengan naik kapal dan bertanya kepada nakhoda kapal, "pernahkah engkau belajar nahw, tata bahasa?" nakhoda kapal menjawab dia tidak pernah belajar tata bahasa, sang nahwi berkata kepadanya, "Oh! Betapa kasihannya dirimu? Separuh hidup yang engkau lalui menjadi siasia." Sang nakhoda hanya diam.

Namun tiba-tiba, badan datang menghantam kapal hingga berada dalam keadaan sangat kritis. Sang nakhoda bertanya, "apakah engkau bisa berenang?" ahli bahasa menjawab ia tidak pernah mau belajar berenang. Sang nakhoda berkata, 'Oh nahwi! Betapa malangnya nasibmu?! Seluruh hidupmu telah sia-sia, karena kapal sdang tenggelam dalam pusaran gelombang dahsyat ini. (Can 2005, 181)

Dalam kisah ini Rumi menggambarkan bahwa betapa orang yang paling terpelajar di suatu bidang, bisa menjadi bodoh dalam bidang yang tidak ia pelajari. Ahli tata bahasa misalnya ia sebagai ahliahli ilmu formal, sedangkan sang nakhoda adalah para sufi. Jadi, sepintar apapun akal, ia hanya bisa menangkap sesuai pengalaman masing-masing. Rumi ingin mengatakan bahwa pengalaman langsung dalam kehidupan lebih penting daripada sekedar ilmu pengetahuan. Orang yang berpengalaman akan lebih mudah menghadapi kehidupan dan mala petaka dibanding orang tak berpengalaman langsung, sekalipun ilmu pengetahuan yang ia miliki banyak. (Baqir 2015, 3-4)

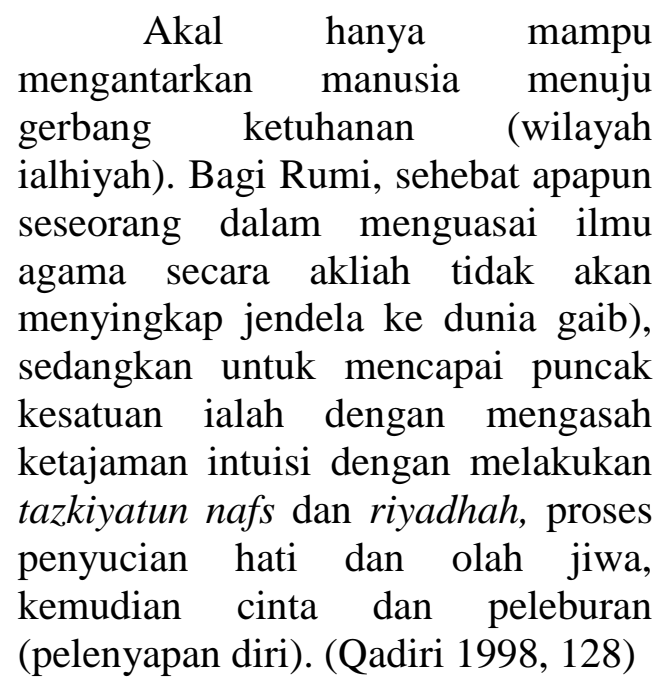

Menurut Rumi perbincangan mengenai eksitensi Tuhan seluas apapun tidak akan mengubah seseorang menjadi lebih baik, sebelum mengalami pengalaman bersama Tuhan. Karena, akal hanya menuntut bukti-bukti tentang Tuhan, sebab akal menelisik melalui penalaran. Sedangkan hati atau jiwa tidak lagi mencari bukti sebab ia sudah melihat dengan lensa penyaksian. Seseorang yang sudah memiliki penglihatan langsung melalui mata jiwa tidak lagi membutuhkan bukti. "ketika engkau telah duduk bersanding dengan kekasihmu, engkau akan mengenyahkan segala perantara", demikian menurut Rumi. Dalam kajian sufistik, ada sebuah uangkapan mengenai fenomena tersebut "man syahadahu istaghna 'anit ta'rif", barangsiapa yang sudah menyaksikan, maka ia tidak lagi membutuhkan definisi.

Perlu digarisbawahi bahwa kritik-kritik Rumi terhadap kapasitas 
akal, sebagai sesuatu yang terpisah dari cinta, harus tidak dipahami dalam seluruh konteks ajaranajarannya, yang di dalamnya akal memainkan peran utama dan positif. Sebab, ia adalah sesuatu yang niscaya dalam menempuh jalan cinta dan penuntun bagi manusia menuju pintu gerbang pelataran Tuhan, sebagaimana Jibril yang berperan sebagai pendamping Nabi ketika melakukan mi'raj. Tetapi, untuk mencapai pada tahap akhir perjalanan, hanya dapat bertumpu pada kaki-kaki cinta dan peniadaan diri.

\subsection{Kekuatan Cinta}

Dalam pandangan Rumi, cinta sebagai dimensi pengalaman rohani sepenuhnya mengendalikan keadaan batin dan psikologis sufi. Ia tidak dapat dijelaskan melalui kata-kata, tetapi hanya dapat dipahami melalui pengalaman. (Chittick 2001, 191192) Rumi sering menegaskan bahwa cinta tak terungkapkan, namun di dalam syair-syairnya Rumi memberikan gambaran tentang cinta, seperti syair berikut;

Cinta adalah ikatan kasih sayang, ia adalah sifat Tuhan

Cinta adalah inti, dunia adalah kulit

Cinta adalah air kehidupan yang akan membebaskanmu dari kematian. Oh, dia adalah seorang raja, yang melemparkan dirinya ke dalam Cinta.
Cinta adalah dasar
samudera kehidupan;
kehidupan abadi adalah
bagian dari
pemberiannya.

Cinta adalah seorang ibu yang akan senantiasa memelihara anaknya.

Cinta adalah kimia "zat mukjizat" ia akan menjadikan tambang makna-makna.

Cinta adalah nyala, yang manakala membara, membakar segalanya kecuali Yang Tercinta. (Marshall 1986, 1)

Konsep cinta Rumi merupakan jalan untuk mencapai kesempurnaan. Ia merupakan jalan untuk membersihkan diri sehingga mengantarkan manusia sampai kepada Tuhan. Pengalaman cinta melampaui semua bentuk kata-kata, ungkapan, konsep, dan pemikiran, cinta justru menjadi pengalaman maha indah yang lebih nyata dari semesta dan memiliki kekuatan dahsyat yang menakjubkan. (Can 2005, 147) Menurut Rumi kesatuan hamba dengan Tuhan, dipatrikan oleh rasa cinta yang murni, menghadapi perjuangan hidup dengan hati yang besar dan insyaf akan "tempat asal mula jadi". (Ahmadi 2017, 201) Meskipun Rumi memberikan gambaran tentang cinta, hal itu hanya dimaksud untuk membangkitkan hasrat menuju cinta dari hati orang yang mendengarnya, seperti syair berikut : 
Cinta membuat yang pahit menjadi manis

Cinta mengubah
tembaga menjadi emas

Cinta mengubah sampah menjadi anggur

Cinta mengalihkan
derita ke dalam
penyembuhan

Cinta menghidupkan yang mati

Cinta mengubah raja menjadi hamba sahaya.

\section{Cinta mendidihkan samudra laksana buih \\ Cinta meluluhlantakkan gunung menjadi pasir.}

Cinta menghancurkan langit beratus keping

Cinta mengguncang
dunia.

Kekuatan cinta ini pula yang mengantarkan seorang pecinta melabuhkan kepasrahan utuh secara menakjubkan kepada Tuhan, sang kekasih abadi.

Berhubungan dengan cinta, menurut Rumi ada dua macam bentuk cinta: cinta imitasi (isyq majazi) dan cinta sejati (isyq haqiqi). Cinta imitasi adalah cinta kita kepada lawan jenis dan segala bentuk keindahan lainnya selain Tuhan. sedangkan cinta sejati adalah cinta kita kepada Tuhan semata. Cinta imitasi bersifat semu, sementara, dan menorehkan kekecewaan bagi siapa pun yang mendekapnya, sedangkan cinta sejati justru bersifat hakiki, abadi, dan membuahkan kebahagiaan bagi siapa pun yang mereguknya.

Bagi Rumi, kesalahan yang terjadi pada manusia duniawi bukanlah masalah kecintaannya pada dunia ini, melainkan ketidakmampuannya untuk merasakan bahwa segala sesuatu di dunia ini tidak lain sebagai bayangan kekasih sejati. Rumi melukiskan dalam syairnya ;

Sang burung terbang
tinggi, sementara
bayang-banyangnya
meluncur di permukaan
bumi, terbang seperti
sang burung.
Orang dungu memburu
bayang-bayang itu,
berlari sampai
kehabisan tenaga.

Tanpa mengetahui bahwa yang dikejarnya hanyalah pantulan dari sang burung di langit, tak menyadari sumber bayang-bayang.

Dengan alasan inilah, Rumi menitahkan kepada umat manusia agar melabuhkan cinta sejati kepada Tuhan semata, sebab cinta kepada selain-Nya akan selalu menorehkan luka di hati sang pencinta.

kekuatan cinta yang sanggup menangkap pengalaman ketuhanan secara utuh adalah melalui wadah hati dengan dua fungsi utama ; pertama, saat seseorang sudah tercerahkan penglihatan spiritualnya melalui penyucian kalbu, saat itulah 
ia telah benar-benar menjadi muhaqqiq, seorang yang sadar akan realitas spiritual dan misteri keberadaan gaib. (Qamber 2002, 162) Di sini, Rumi mengajak manusia untuk senantiasa menyucikan hatinya dengan selalu menjauhi maksiat dan mengerjakan ketaaatan sehingga kalbunya menjadi tajam dan jernih di mana isyarat-isyarat ketuhanan akan terpantul di permukaan hatinya, menyaksikan dengan penglihatan kepastian. (Sharif 1995, 2)

Kedua, cinta Tuhan akan menyapa hambanya yang telah melakukan penyucian hati, mengosongkan kalbu dari segala sesuatu selain-Nya semata, "selama masih ada jejak kecintaan diri dalam dirimu, Allah tidak akan menunjukkan wajah-Nya kepadamu" nasihat Maulana Rumi. (Zaprulkhan 2016, 201-203) Oleh karena itu, selama ego dan kecintaan terhadap dunia masih bersemayam dalam hati, selama itu pula kita tidak dapat mencapai puncak cinta yang sejati. Akhirnya, ketika seseorang telah menjernihkan hatinya dari segala karat duniawi, mengosongkan hatinya dari semua bentuk dualitas, dan menghiasinya dengan cinta sakral Ilahi semata, saat itulah ia akan menjelma seorang "manusia Tuhan". (Sharif 1995, 2) manusia ideal yang menjadi cerminan dari keindahan Sang Ilahi.

\section{Manifestasi Cinta Jalaluddin Rumi dalam Tarian Whirling Dervishes}

Whirling Dervhises atau tarian berputar sufi merupakan tarian yang dikembangkan dari ajaran sufisme Jalaluddin Rumi. Tarian berputar ini menjadi ciri khas dari tarekat Maulawiyah yang dikembangkan oleh Sultan Walad, anak laki-laki dari Syekh Jalaluddin Rumi.

Dalam hal ini, Rumi mampu menghadirkan ajaran-ajaran sufisme, yang dipadukan dengan sastra musik dan seni, ia menciptakan sebuah tarian sufi untuk mencapai keindahan Tuhan. Tarian berputar ini bermula ketika Rumi mengalami kesedihan yang mendalam karena ditinggalkan oleh sang mentari yakni Syams Tabriz. Setelah kepergian Syams Tabriz, Rumi merasa kehilangan belahan jiwa dan sahabat yang selalu membimbingnya. (Murdiati 2011, 1314)

Karena merasakan kesedihan
yang mendalam, Rumi lalu
mengunjungii sahabatnya
Shalahuddin Zarkub dengan niat
untuk menghibur diri atas
kesedihannya. Shalahuddin Zarkub
merupakan seorang yang pandai besi,
menurut Rumi irama dentuman besi
yang didengarnya seakan berzikir
menyebut nama "Allah", hal itu
mengakibatkan Rumi berada dalam
keadaan ekstase, dan menari berputar
mengikuti iraman dentuman besi
tersebut. (Schimmel 2000, 24)

Pesona Jalaluddin Rumi memancar dari ritual meditasi sufistiknya, musik dan tarian berputar menjadi ciri khas kelompok tarekat ini. Tarian yang sangat dekat dengan pemikiran sufustik, menjadi jalan bagi Rumi dalam melepaskan kesedihannya atas kepergian Syams Tabriz, ia mengekpresikan kesedihannya dengan berputar-putar. 
Bagi Rumi, pengalaman langsung Ilahiyah melalui suara musik lebih mudah menyentuh hatinya dibandingkan membaca beberapa karya mistik Islam. Tarian mistik ini membuka jalan untuk menuju Tuhan, bahkan ia menjadi aspek penting sekaligus sebagai poros utama dari syair Rumi. Dalam syairnya, Rumi mengatakan bahwa tarian tersebut adalah perumpamaan dari tangga yang dapat digunakan setiap jiwa yang merindu untuk mencapai penyatuan dengan sang kekasih.

Gerakan berputar tersebut memiliki makna tersendiri, untuk menemukan tujuan hidup yang hakiki, yaitu mencari Tuhan dan merasakannya dalam gerakan yang berputar, dengan putaran yang berlawanan arah jarum jam. Penari sufi harus menanggalkan semua emosi, agar hanya merasakan kecintaan dan kerinduan yang mendalam pada Tuhan.

Adapun makna simbolis dari Tarian berputar sufi sebagai berikut :

a. Posisi tangan; tangan kanan menunjuk keatas yang berarti menjemput hidayah dari Allah, kemudian tangan kiri menghadap ke bawah yang berarti jika hidayah sudah didapatkan maka harus disebarkan ke bawah (sesama manusia).

b. Berputar yang berlawanan dengan arah jarum jam ; memiliki makna filosofi bahwa gerak spiritual manusia harus menciptakan hubungan yang vertikal menuju (Tuhan). c. Topi yang panjang/tinggi ; mengisyaratkan sebuah kuburan/nisan yang berarti kuburan dari ego, nafsu dan hasrat duniawi.

d. Baju berwarna putih ; jika ego, nafsu dan hasrat duniawi sudah terkubur, maka isilah dengan cahaya kesucian.

e. Kondisi dasar semua yang ada di dunia ialah berputar, begitu juga dengan manusia. Manusia mengalami perputaran dari tidak ada, menjadi ada, untuk kemudian kembali menjadi tiada.

f. Bergerak menyatu dengan perputaran keseluruhan ciptaan; yang menggambarkan perjalanan spiritual manusia dengan cita dalam menggapai kesempurnaan. (Faiz, 2019)

\section{KESIMPULAN}

Jalaluddin Rumi yang merupakan tokoh besar sufi, sangat populer dengan karya-karya monumetalnya. Pemikiran tasawufnya disajikan dalam bentuk yang berbeda dari tokoh-tokoh sufi pada masanya, tetapi hal itu tidak mengurangi makna yang terkandung di dalam setiap karyanya. Bahkan bentuk sufisme demikian membuat karya-karyanya dikagumi dan djadikan bahan renungan dan kajian di dunia Islam maupun Barat.

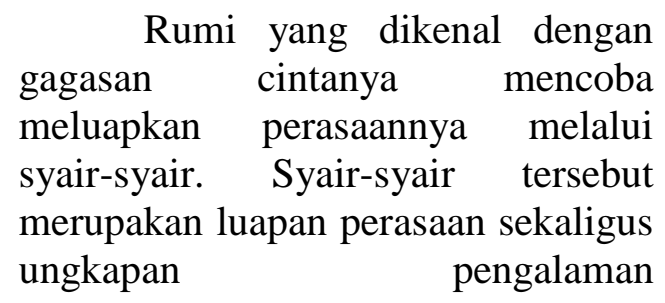


keberagamaannya yang personal, yang lahir dari hati yang merindukan penyatuan diri dengan Sang Kekasih. Sampai ketika Wujud Kekasih menjadi satu-satunya wujud yang ada

Menurut Rumi, cinta yang merupakan cahaya kehidupan dan

\section{Daftar Kepustakaan}

A.J. Arberry. Discourses of Rumi. Malaysia: Thinker's Li brary SDN. BHD, 1996.

Ahmadi, Rizqa. "JEJAK SANG PENYAIR PERSIA: CORAK SASTRA SUFISTIK JALALUDDIN MUHAMMAD MAULAVI DALAM KARYANYA 'MATSNAWI."' Jurnal CMES, 2017. doi:10.20961/cmes.6.2.1171 8.

Baqir, Haidar. Belajar Hidup Dari Rumi. Jakarta: Penerbit Mizania, 2015.

Chittick, William C. Jalan Cinta Sang Sufi: Ajaran-Ajaran Spiritual Jalaluddin Rumi. Yogyakarta: Penerbit Qalam, 2001.

Chuliyeva, Vasila Erkinovna. "THE INTELLECTUAL AND COLLABORATE ISSUES IN THE PHILOSOPHICAL PROPOSALS OF JALOLIDDIN." Theoretical \& Applied Science, 2018. doi:10.15863/tas.2018.09.65 30 . nilai manusia ini, sesungguhnya bersifat kekal. Jadi harus diperuntukkan kepada yang kekal pula. Ia tidak pantas diberikan $\mathrm{k}$ epada yang ditakdirkan menjadi fana dan binasa.

Cyrus Masrori. “An Islamic Language of Toleration: Rumi's Criticism of Religious Persuation." Published by: University of Utah 63, no. 2 (2010): 24445.

Isa, Syeikh Abdul Qadir. Cetak Biru Tasawuf: Spiritual Ideal Dalam Islam. (Ciputat: Ciputat Press, 2007.

Jack Marshall. "After Rumi." Published by: Old City Publishing 15, no. 1 (1986): 1.

Jalaluddin Rumi. Fihi Ma Fihi: Mengarungi Samudera Kebijaksanaan. Edited by Penj. Abdul Latif. Yogyakarta: FORUM, 2018.

Kabir Helminski. Meditasi Hati: Transformasi Sufistik. bandung: Pustaka Hidayah (IKAPI), 2005.

Khodady L, the Others. "Factors Which Influence Love Based Human Relationship in Jalaluddin Rumi's View in His Masnavi." Journal of Stylistic of Persian Poem 
and Prose (Bahar E-Adab), 8, no, 2 (2015): 205.

Laily Mansur. Ajaran Dan Teladan Para Sufi. Jakarta: PT Raja Grafindo Persada, 1996.

Manijeh Manni. "The Metaphysics of the Heart in the Sufi Poetry of Rumi." The University of Notre Dame 42, no. 3 (2010): 164.

Muhammad Riaz qadiri. The Sayings and Teachings of the 101 Great Mystics of Islam. New Delhi: Adam Publisher and Distributors, 128AD.

Mukti Ali. Islam Mazhab Cinta: Cara Sufi Memandang Dunia, (Bandung: Mizan (IKAPI), 2015), Hal. 274. bandung: Mizan (IKAPI), 2015.

Mulyadi Kartanegara. Jalal Al-Din Rumi: Guru Sufi Dan Penyair Agung. Traju, 2014

Murdiati, Eni, Tarian Spiritual Jalaluddin Rumi, Jurnal Wardah, vol. Xxii, no. 22, 2011.

Permadi. Pengantar Ilmu Tasawuf. Jakarta: PT Rineka Cipta, 1997.

Qamber, Akhtar. "ESSAY: RUMI: Mystic Extraordinary." International Centre Quarterly India 28, no. 4 (2002): 162.

Rifa'i, Bachrun. dkk. Filsafat
Manusia, Bandung: Pustaka Setia, 2010.

Rochelle Sammel. Emosi: Bagaimana Mengenal, Menerima, Dan Mengarahkannya.

Yogyakarta: Kanisius, 1986

Rumi, Jalaluddin. Diwan Syams Tabrizi. Yogyakarta: FORUM, 2018.

-. Masnawi; Senandung Cinta Abadi Jalaluddin Rumi. Edited by penj. Abdul Hadi. Yogyakarta: Rausyan Fikr Institute, 2013.

Rustom, Mohammed. "Rumi's Metaphysics of the Heart." Mawlana Rumi Review, 2018

doi:10.1163/2589856600101007.

Sefik Can. Fundamentals of Rumi's Thought A Mevlevi Sufi Perspective. 1st ed. (New Jersey: By The Light, Inc and Isik Yayinlari, 2005.

Schimmel, Annemarie, Dunia Rumi: Hidup dan Karya Penyair Besar Sufi, Yogyakarta: Pustaka Sufi, 2000. , Rahasia Wajah Suci Ilahi: Memahami Islam Secara Fenomenologis, Bandung: Penerbit Mizan, 1996.

Sharif, M.M. "A History of Muslim Philoshophy." Delhi : Low Price Publication 2 (1995): 2.

Stephen Kinzer. "Festival of Rumi, 
Miftahul. J:,Teologi Suifi : Kajian Mistisisme.. 52

Poet of Life's Dance, Sunil Sharma. "Reading the Act and Section A, Page 4, 1998, p. Lives of Performers in 2." Konya Journal 4 (1998): Mughal Persian Texts." 2. JSTOR, 2015, . 188. 